\title{
Amino-oxyacetic acid: Effects on multiple fixed ratio-fixed interval performance in the rat'
}

\author{
J. W. MeKearney and R. A. Patton \\ UNIVERSITY OF PITTSBURGH
}

\begin{abstract}
Abstraet
Disruptions in multiple FI-FR operant performance as a function of administration of amino-oxyacetic acid, a drug which increases brain levels of gamma-aminobutryic acid, were studied. The drug caused profound disruptions in response rate and temporal patterning, but these effects were not temporally correlated with the time-course of neurochemical effects reported by other investigators.
\end{abstract}

\section{Problem}

Despite the great volume of research on the possible role of gamma-aminobutyric acid (GABA) in the central nervous system, behavioral investigations have been relatively sparse. This is probably, at least in part, due to the fact that GABA, in common with most of the endogenous neuroactive substances, has difficulty in passing the blood-brain barrier when injected parenterally. An increasingly popular method of studying such substances is to make use of compounds which, after parenteral injection, enter brain and there interact, in a known fashion, with the particular neurochemical system of interest (see, e.g., Poschel \& Ninteman, 1963, 1964; Carlton, 1963).

Amino-oxyacetic acid $\left(\mathrm{H}_{2} \mathrm{NOCH}_{2} \mathrm{COOH}\right)$ has been shown (Wallach, 1960; Roberts, 1963) to be a potent inhibitor of GABA-a-ketoglutarate transaminase (GABA-T) in brain. GABA-T is the enzyme responsible for catalyzing the first step in the metabolic decomposition of GABA, and thus, parenteral administration of amino-oxyacetic acid (AOAA) results in significant increases in total brain levels of GABA (Wallach, 1960; Roberts, 1963; DeVanzo et al, 1961). AOAA itself has been shown to have some efficacy as an anticonvulsive (DeVanzo et al, 1961; Roa et al, 1962) but there seems to be no direct correlation between GABA level and degree of seizure protection, suggesting that some other system might mediate this effect of AOAA.

The purpose of the present study was to determine some of the behavioral effects of AOAA, and to determine whether these effects reliably parallel the timerelated changes in brain GABA level, as reported by Roberts (1963) and others. If the behavioral effects of similar dosages, on a similar species, were found to be highly correlated with the available biochemical data, one might have some justification for suspecting that the behavioral effects were being mediated by changes in brain GABA level.

\section{Method}

Male Sprague-Dawley rats were trained to press a lever for a small amount of water reinforcement. After initial training they were placed on a multiple fixed- interval (2 min.), fixed-ratio (10) schedule of reinforcement (Ferster \& Skinner, 1957). The two components alternated after each reinforcement, one being signalled by a tone, and the other by a clicking sound. The animals, under $23 \mathrm{hr}$. water deprivation, were tested daily for 40 min. periods until such time as their performance was extremely stable from day-to-day.

Amino-oxyacetic acid hemihydrochloride (Eastman Organic Chemicals) was dissolved in sterile water (25 mg total salt per $\mathrm{cc}$ ) and injected intraperitoneally in dosages of $50,25,12.5$ or $6.25 \mathrm{mg} / \mathrm{kg}$ at time intervals of $1,4,8$ or $16 \mathrm{hr}$. before the test period. Isotonic saline $(0.5 \mathrm{cc})$ was used as a placebo, and was administered at the same pre-test intervals as the drug.

\section{Results}

Figure 1 shows dose- and time-related effects of AOAA on two parameters of performance. The upper portion of the figure shows changes in total response rate, expressed as percent of normal, and the lower portion depicts the concurrent changes in response
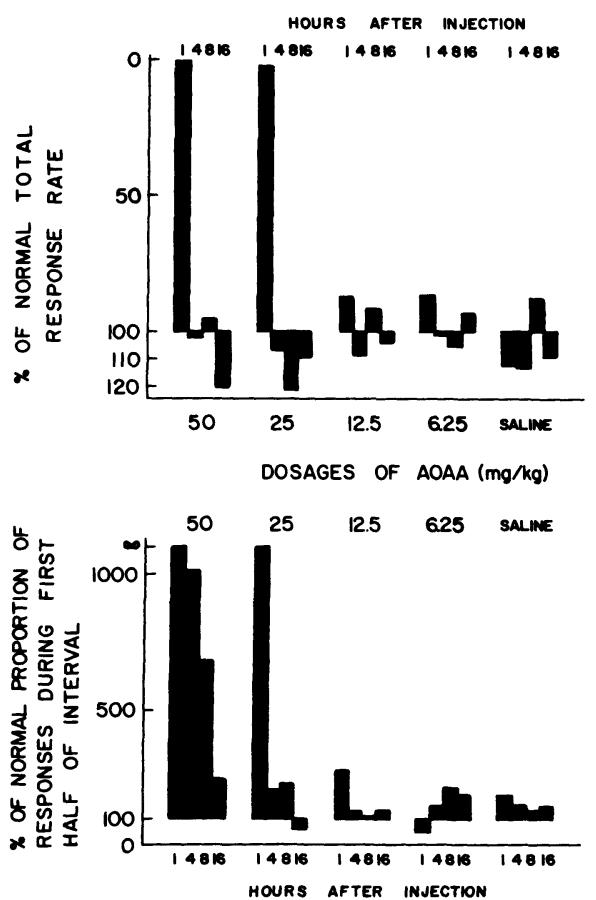

Fig. 1. Summary of effects of AOAA on response rate and temporal patterning. Each bar represents averaged data from two animals, their means for a three day pre-drug period serving as the baseline. Each set of four bars represents successively smaller dosages of drug, and the placebo, while each bar within a set represents successively increasing injection-test time intervals. 
patterning during the fixed-interval component of the schedule, expressed as percent of the proportion of responses normally emitted during the first half of the interval (cumulated over a $40 \mathrm{~min}$. session). For both measures, the mean of the three day pre-drug period was used as the baseline.

At $50 \mathrm{mg} / \mathrm{kg}$ there was a severe disruption of both rate and temporal pattern at $1 \mathrm{hr}$. Following this, however, the rate returned to approximately normal levels, with a hint of a possible stimulatory effect at $16 \mathrm{hr}$. In contrast to this rather brief effect on rate, the temporal patterning was severely disrupted at 4 and $8 \mathrm{hr}$., approaching normal at $16 \mathrm{hr}$. With $25 \mathrm{mg} / \mathrm{kg}$ the picture was much the same, while at $12.5 \mathrm{mg} / \mathrm{kg}$ there was no appreciable effect on rate, and only moderate disruption of temporal patterning during the $1 \mathrm{hr}$. test period. With $6.25 \mathrm{mg} / \mathrm{kg}$, as with the placebo, the effects at all periods were generally slight and apparently random. Thus, with all effective dosages, operant performance was most severely disrupted at $1 \mathrm{hr}$. after injection, thereafter gradually returning to normal.

\section{Discussion}

The specific time-course of these effects is difficult to interpret in terms of changes in total brain GABA levels. If the correlation were high, one would expect maximal behavioral changes to coincide, temporally, with maximal neurochemical change. However, while the behavioral disruption was maximal at $1 \mathrm{hr}$. after injection, the previously published biochemical data (Wallach, 1960; DeVanzo et al, 1961; Roberts, 1963) indicate that maximum GABA levels are not reached for 3 to $6 \mathrm{hr}$. after AOAA administration. Roberts (1963) has reported that, after injection of $50 \mathrm{mg} / \mathrm{kg}$ in the rat, GABA levels are $135 \%$ of normal at $1 \mathrm{hr}$. and $320 \%$ of normal at $3 \mathrm{hr}$. Thus, the animals in the present experiment were beginning to show considerable recovery at a time when, presumably, their total GABA levels were maximal. At $16 \mathrm{hr}$., when performance was essentially normal, Roberts' data indicate that GABA level would still be quite supranormal (220\% of control). Quite clearly, any explanation of the behavioral effects of AOAA simply in terms of total brain GABA levels seems untenable. It is interesting to note that other investigators (DeVanzo et al, 1961) have found a similar apparent dissociation between GABA level and seizure protection after AOAA administration.

The rejection of a simple "total level" explanation appears to leave at least three other possibilities: (a) The behavioral effects may be mediated by some other endogenous neurochemical system affected by AOAA, which may or may not interact with the effect on the GABA system; (b) AOAA may have some per se depressant action which is unrelated to its effect on the GABA system; or, (c) The behavioral effects might be correlated with the amount of "free" as opposed to "total" (i.e., free + bound) GABA which is available to receptor sites.

In summary, on the basis of available biochemical evidence the behavioral effects of AOAA reported here cannot be explained in terms of the effects of this compound on the GABA system.

\section{References}

CARLTON, P. L. Cholinergic mechanisms in the control of behavior by the brain. Psychol. Rev., 1963, 70, 19-39.

DeVANZO, J. P., GREIG, M. E., \& CRONIN, M. A. Anticonvulsive properties of amino-oxyacetic acid. Amer. J. Physiol., 1961, 201, 833-837.

FERSTER, C. B., \& SKINNER, B. F. Schedules of reinforcement. New York: Appleton-Century-Crofts, 1957.

POSCHEL, B. P.H., \& NINTEMAN, F.W. Norephinephrine: a possible excitatory neurohormone of the reward system. Life Sci., 1963, 2, 782-788.

POSCHEL, B.P.H., \& NINTEMAN, F.W. Excitatory (antidepressant?) effects of monoamine oxidase inhibitors on the reward system of the brain. Life Sci., 1964, 3, 903-910.

ROA, P. D., TEWS, J. K., \& STONE, W. E. Anti-convulsive and neurochemical effects of amino-oxyacetic acid. Physiologist, 1962, 5, 204. (Abstract)

ROBERTS, E. Gamma-aminobutyric acid (GABA) - vitamin B6 relationships in the brain. Amer. Jo clin. Nutr o, 1963, 12, 291-307.

WALLACH, D. P. Studies on the GABA pathway-1: The inhibition of gamma-aminobutyric acid-alpha-ketoglutaric acid transaminase in vitro and in vivo by U-7524 (amino-oxyacetic acid). Biochem. Pharmacol., 1960, 5, 323-331.

Note

1. This research was supported by grant MH07227-02 from the National Institute of Mental Health. 